\title{
Aulas experimentais para um Ensino de Química mais satisfatório
}

José Ossian Gadelha de Lima jose.lima@uece.br

$-3645$

Universidade Estadual do Ceará,

Fortaleza, Ceará, Brasil.

Idarlene Marcelino Rodrigues Alves

idarlene.puraquimica@gmail.com

0000-0001-5639-4318

Universidacos

Fortaleza, Ceará, Brasil.
RESUMO

O objetivo deste trabalho foi apresentar os resultados de uma pesquisa que buscou identificar a opinião dos alunos do Ensino Médio sobre as aulas teóricas e as aulas práticas no aprendizado de Química. Para obtenção dos dados, foi aplicado um questionário a 226 alunos das três séries do Ensino Médio. Ao analisarmos as respostas, percebemos que os professores de Química desses alunos raramente desenvolvem uma didática baseada em aulas experimentais. Um Ensino de Química mais satisfatório, segundo os entrevistados, demanda mais aulas dessa natureza, pois tornam esta Ciência mais interessante e motivadora. Os alunos também salientaram a necessidade de um ensino mais contextualizado, com aulas apresentando maior clareza e objetividade.

PALAVRAS-CHAVE: Ensino de química. Aula experimental. Aula expositiva. 


\section{INTRODUÇÃO}

A Química é uma Ciência que estuda as mais diversas transformações e reações que ocorrem com as diferentes substâncias existentes no universo. Seus conhecimentos estão baseados em observações ou experimentações a partir das quais se constroem seus princípios, suas leis e suas teorias (BUONFIGLIO, 2011).

Nessa dimensão, Cardoso e Colinvaux (2000) consideram que, como a Química se constitui em uma das principais ciências que contribuem para o avanço tecnológico da humanidade, é imprescindível que a formação escolar de um cidadão passe pelo estudo de seus conteúdos, principalmente ao se observar que estes conhecimentos estão imbricados nas mais diversas áreas da vida humana. Silva (2011) descreve muito categoricamente esta relação:

A humanidade vive um processo acelerado de modificações e rupturas, que se reflete em todos os setores da sociedade. Assim sendo, a educação e a informação assumem papel significativo neste processo. [...] a Química é uma Ciência vital para a melhoria da qualidade de vida do ser humano (SILVA, 2011, p. 7).

De acordo com Mateus (2010), a importância da disciplina de Química na formação intelectual dos estudantes do Ensino Médio é inquestionável, porém observa-se que muitos estudantes demonstram uma acentuada desmotivação para o seu estudo. Graças às aulas estritamente expositivas e ao completo descaso com a parte experimental, muitos alunos acabam considerando a disciplina 'chata', acreditando ser 'coisa só para cientistas', ou pior ainda, como 'coisa de doido'.

Estas constatações contribuíram para que, ao longo das últimas décadas, o Ensino de Química se tornasse um assunto cada vez mais debatido por educadores e estudiosos. Colaborando com estas discussões, Trevisan e Martins (2008) certificam que as pesquisas desenvolvidas na área de ensino desta Ciência têm-se concentrado principalmente nos mecanismos didáticos que tratam da compreensão dos conteúdos químicos, abordando de forma particular os processos de ensino e de aprendizagem.

Para Alves (2007), quando são utilizadas apenas aulas expositivas, elas acabam se tornando monótonas, fazendo com que seus conteúdos sejam de difícil compreensão. Por outro lado, se o ensino for conduzido somente por meio de aulas experimentais, os conhecimentos trabalhados não serão assimilados de forma satisfatória, pois a prática do experimento necessita de um embasamento teórico para dar sustentação à compreensão dos conteúdos. Todavia, sob o ponto de vista de Silva e Machado (2008), o aprendizado de Química tornou-se muito difícil para os nossos alunos e, possivelmente, uma das causas desta constatação seja a completa falta de uma concepção didática capaz de promover a associação entre os aspectos teóricos e práticos da disciplina.

Neste sentido, segundo Leal (2010), a experimentação no Ensino de Química é capaz de levar o aluno a compreender que os conceitos químicos, em geral considerados bastante abstratos, foram construídos a partir de procedimentos experimentais dos quais muitos podem ser observados ou reproduzidos por ele mesmo. Pinto (2012) corrobora esta assertiva ao afirmar que um Ensino de Química satisfatório só será possível quando sua didática for capaz de mostrar ao estudante, de forma clara, objetiva e interessante, a íntima relação que existe 
entre os conhecimentos teóricos da disciplina e os experimentos que levaram os pesquisadores às descobertas destes conhecimentos.

A partir destas conjecturas, o objetivo deste trabalho foi apresentar o resultado de uma pesquisa que buscou discutir, sob o ponto de vista de alguns alunos do Ensino Médio, a respeito das contribuições das aulas teórico-expositivas e das aulas prático-experimentais para o processo de ensino e de aprendizagem da disciplina de Química.

A partir das respostas dos alunos, dadas a um questionário preparado especialmente para se conhecer o pensamento e os sentimentos destes estudantes sobre essas duas estratégias didáticas utilizadas no Ensino de Química, foi possível conhecer suas opiniões, desejos, angústias e esperanças sobre a temática, abrindo espaço para que esses sujeitos, os mais implicados em todo o processo educativo, possam participar das numerosas discussões que ora se intensificam como tentativa de buscar uma educação de melhor qualidade para todos.

\section{METODOLOGIA}

A abordagem desta pesquisa caracterizou-se como qualitativa, sem, no entanto, negligenciar o aspecto quantitativo. Neste sentido, as opiniões, as críticas, as manifestações de sentimentos e os comentários dos alunos foram instrumentos importantes durante o processo de análise e interpretação qualitativa dos dados da pesquisa (MALHEIROS, 2011).

Quanto aos objetivos, a investigação pode ser classificada como exploratória, pois teve a intenção de conhecer a opinião destes alunos a respeito das aulas teóricas e das aulas práticas desenvolvidas pelos professores de Química de algumas Escolas Pública de Crateús-CE.

Com a finalidade de coletar os dados necessários ao desenvolvimento das discussões apresentadas nesta investigação, utilizamos a técnica da pesquisa de campo (LÜDKE; ANDRÉ, 2013), a qual foi realizada por meio da aplicação de um questionário composto por 12 (doze) questões: 09 (nove) objetivas, em que os alunos tinham a opção de escolher uma resposta, e 03 (três) subjetivas, nas quais os alunos tinham a oportunidade de criticar, comentar e, até mesmo, manifestar seus sentimentos com relação às aulas de Química.

Desse modo, as respostas dos alunos ao questionário constituíram o aporte empírico desta investigação, que foi discutido à luz do referencial teórico fundamentado em pesquisas dos principais autores já consagrados na literatura e em documentos oficiais divulgados pelo Ministério da Educação (BRASIL, 1999; 2002; 2006).

Para o desenvolvimento da etapa da pesquisa de campo, selecionamos 04 (quatro) escolas de Ensino Médio na cidade de Crateús-CE. O motivo da escolha dessas escolas se apoia, principalmente, no fato de apresentarem um espaço apropriado no qual funcionaria um laboratório de ciências. Um total de 226 (duzentos e vinte seis) estudantes destas escolas, distribuídos por turmas das três séries do Ensino Médio $\left(1^{\circ}, 2^{\circ}\right.$ e $\left.3^{\circ}\right)$, dos três turnos (manhã, tarde e noite), responderam ao questionário. 
Durante o planejamento dos trabalhos relacionados à participação dos alunos, foi explicado a eles que suas respectivas colaborações, de modo algum, teria caráter obrigatório. Então, pedimos a todos que, por vontade própria e voluntariamente, disponibilizassem um pouco de seu tempo a fim de contribuir para a pesquisa. Dessa forma, conseguimos a participação de todos os alunos presentes na escola e nas turmas trabalhadas durante os dias de aplicação do questionário.

\section{RESULTADOS E DISCUSSÃO}

A seguir apresentamos o relatório da pesquisa de campo, atendendo à seguinte sistemática: reprodução da questão como foi apresentada ao aluno no questionário; apresentação dos resultados das respostas dadas pelos alunos e a análise percentual dos números correspondentes a cada uma delas; e, por último, exposição das considerações e reflexões a respeito desses resultados fundamentadas no referencial teórico utilizado.

\section{1a questão: Você considera a Química:}

\section{a) ( ) uma coisa só pra cientista b) ( ) não tem sentido na minha vida} vida

c) ( ) coisa de gente doida d) ( ) um conjunto de saberes ligados à minha

Resultado: 12,8 \% (29 alunos) assinalaram a opção a; 2,6\% (06 alunos) a opção b; 3,1\% (07 alunos) a opção c; e 81,4\% (184 alunos) a opção d.

De acordo com os resultados das respostas a esta questão, podemos observar que mais de $80,0 \%$ destes alunos do Ensino Médio consideram que os conhecimentos tratados na disciplina de Química estão ligados à sua vida.

Segundo as Orientações Curriculares para o Ensino Médio (OCEM) de Química (BRASIL, 2006), esta Ciência deve ser capaz de, enquanto instrumento de formação dos seres humanos, alargar os horizontes dos cidadãos, tanto no aspecto cultural quanto na autonomia do agir em sociedade. No entanto, para que isso seja possível, é necessário que esse conhecimento promova uma interpretação de mundo e torne os sujeitos competentes para intervir na realidade. Deste modo, para que a Química possa contribuir efetivamente para a formação do indivíduo, torna-se imprescindível que seus conhecimentos, conceitos, métodos e linguagens próprias, sejam apresentados como Ciência, relacionados ao desenvolvimento científico e tecnológico e à vida do planeta e em sociedade.

Para Pinto (2012), por meio da realização de práticas experimentais é possível oportunizar ao aluno, tanto do Ensino Médio quanto do Superior, conhecer a essência da Química, descobrindo sua importância e a estreita relação desta Ciência com a natureza que a cerca. Os experimentos propiciam também ao estudante oportunidades de familiarização com o processo científico, adquirindo uma compreensão mais desmistificadora do 'fazer ciência'. Segundo Rushton, Lotter e Singer (2011), além de despertar o interesse dos alunos, as aulas experimentais proporcionam também uma maior e melhor divulgação da ciência, salientando seu aspecto positivo, contribuindo assim para o processo de alfabetização científica. 
O aprendizado de Química pelos alunos de Ensino Médio implica que eles compreendam as transformações químicas que ocorrem no mundo físico de forma abrangente e integrada e assim possam julgar com fundamentos as informações advindas da tradição cultural, da mídia e da própria escola e tomar decisões autonomamente, enquanto indivíduos e cidadãos (BRASIL, 1999, p. 31).

Portanto, os conhecimentos desta Ciência devem estar ligados à vida do estudante, pois só dessa maneira terá sentido estudá-los. Esses conhecimentos deveriam também ser capazes de possibilitar ao aluno: aprender a pensar, desenvolver raciocínio, explicar os fenômenos da natureza, tomar consciência da importância da preservação, tornar sua vida mais interessante, estimular sua criatividade, incentivar o prazer da descoberta, entender as mudanças no avanço tecnológico, divertir-se aprendendo, enfim, perceber que a Química é um conjunto de saberes que ajudam a compreender melhor o mundo e, portanto, a torná-lo um cidadão mais consciente e atuante.

2a questão: Quanto aos assuntos da disciplina de Química, você os considera de:

\section{a)（） Fácil Compreensão b)（） Difícil Compreensão c)（）Muito Difícil Compreensão}

Resultado: 42,4\% (96 alunos) marcaram a opção a; 53,6\% (121 alunos), a opção b; e 4\% (09 alunos), a opção c.

Por meio das respostas dos alunos, notamos que a maioria deles considera os assuntos da disciplina de Química de 'difícil compreensão'. Segundo Maia, Silva e Wartha (2008), isso ainda acontece porque as aulas, de modo geral, continuam a ser didaticamente trabalhadas da maneira tradicional, contribuindo para dificultar a assimilação dos conteúdos.

Para Gerhard e Filho (2012), a falta de contextualização e interdisciplinaridade entre as disciplinas escolares também dificulta a aprendizagem dos alunos, já que:

[...] a aprendizagem é sempre relacional, isto é, os seres humanos aprendem relacionando novas informações a conhecimentos anteriores, pois somente assim as informações ganham sentidos, sem os quais não ocorre aprendizagem (GERHARD; FILHO, 2012, p. 126).

Corroborando estas afirmações, de acordo com as OCEM (BRASIL, 2006), ainda não ocorreu uma inovação didática nas metodologias aplicadas pelos professores no ensino de todas as disciplinas, apesar da exortação a esta renovação ter se iniciado há quinze anos, com a publicação dos PCNEM:

\footnotetext{
No entanto, a prática curricular corrente, apesar de já passados sete anos desde a divulgação dos PCNEM, continua sendo predominantemente disciplinar, com visão linear e fragmentada dos conhecimentos na estrutura das próprias disciplinas, a despeito de inúmeras experiências levadas a cabo no âmbito de projetos pedagógicos influenciados pelos Parâmetros (BRASIL, 2006, p. 101).
} 
Essa realidade persistente contribui para dar continuidade a um aprendizado considerado difícil, enfadonho e sem fundamento. A difícil compreensão dos conteúdos químicos é um dos principais fatores que contribuem para os baixos índices de aprendizado, além de colaborar para uma completa falta de motivação ao estudo da disciplina pelos discentes. Essas dificuldades se baseiam no fato de muitos professores ministrarem conteúdos de Química sem ter o aporte didático necessário e, por conseguinte, sem uma metodologia adequada. A preocupação maior desses profissionais é a transmissão das informações, sem qualquer preocupação com a realidade dos discentes, nem com os saberes que eles trazem.

No Ensino de Química, de acordo com Guimarães (2009, p. 198), “a experimentação pode ser uma estratégia eficiente para a criação de problemas reais que permitam a contextualização e o estímulo de questionamentos de investigação", ajudando o aluno a atingir sucesso no seu aprendizado.

3a questão: Com que frequência são realizadas aulas práticas de Química no laboratório?

\section{a) ( ) Frequentemente b) ( ) Raramente c) ( ) Nunca}

Resultados: 20,3\% (46 alunos) assinalaram a opção a; 70,8\% (160 alunos), a opção b; e 8,9\% (20 alunos), a opção c.

É muito preocupante e perturbador observar que 160 alunos, ou seja, 70,8\% assinalaram que as aulas práticas de Química no laboratório são realizadas raramente.

Como a escola dos alunos entrevistados apresentava laboratório de ciências, é extremamente desanimador perceber que os professores não têm utilizado essa ferramenta de maneira mais frequente a seu favor, já que por meio da realização de experimentos é possível, didaticamente, despertar a curiosidade dos alunos e, consequentemente, torná-los mais interessados em estudar os conteúdos de Química (RUSHTON; LOTTER; SINGER, 2011).

Nesta perspectiva, Borges (2002) assevera que, ao trabalhar no laboratório, os discentes têm a oportunidade de interagir com os equipamentos, vidrarias, reagentes, e outros materiais com os quais eles não teriam contato em sala de aula.

Alves (2014), por outro lado, chama a atenção para os aspectos relacionados às dificuldades na realização da experimentação nas aulas de Química. Para esta estudiosa, um dos maiores empecilhos se refere à formação inicial docente. Durante esse processo, o licenciando praticamente não tem contato com técnicas didáticas fundamentadas em aulas experimentais, implicando em profissionais que não conseguem trabalhar de maneira adequada a parte experimental dos conteúdos da Química (BENITE; BENITE; ECHEVERRÍA, 2010).

Os dados dessa pesquisa corroboram as proposições de Leite (2001, p. 93) para quem o trabalho no laboratório "continua a ter um baixo grau de abertura, a servir, essencialmente, para confirmar conteúdos previamente leccionados e a exigir pouco envolvimento da parte dos alunos".

Temos a considerar também que os docentes, muitas vezes, não têm interesse em desenvolver aulas experimentais, pois, segundo Calil (2009), muitas escolas apresentam espaço físico apropriado ao laboratório, mas faltam os equipamentos, 
as vidrarias e os reagentes necessários. Experimentos simples, com materiais baratos e de fácil obtenção, e sendo bem planejados, podem fazer uma grande diferença na aprendizagem dos alunos, além de contribuir para a percepção do caráter experimental da Química.

4 a questão: Seu professor de Química já fez experiências químicas na sala de aula?

\section{a) ( ) $\operatorname{sim}$ b) ( ) não}

Resultado: 22,5\% (51 alunos) assinalaram a opção a; e 77,5\% (175 alunos), a opção b.

Observamos que 77,5\% dos alunos assinalaram a opção 'não', ou seja, a maioria dos alunos não teve a oportunidade de assistir ou participar de experiências simples que poderiam ser conduzidas na própria sala de aula. Esta realidade ainda é a de muitas Escolas Públicas no Brasil (MALDANER, 2006).

Galiazzi e Gonçalves (2004) afirmam que a inexistência de laboratório na escola não é justificativa para a predominância suprema de aulas expositivas. A utilização de materiais alternativos é capaz de suprir grande parte das necessidades referentes a sua falta, além de tornar o processo de ensino e de aprendizagem mais proveitoso. Essas iniciativas mostram que a realização de experimentos pode ser conduzida também fora do laboratório de ciências, o que comprova não ser somente por meio deste espaço que serão alcançados bons resultados para melhorar a qualidade do Ensino.

Esta realidade nos faz reportar a Alves (2007), para quem a prática pedagógica depende de três fatores: qualidade básica, habilidade pessoal e estar preparado tanto nas aulas teóricas como nas aulas práticas. Então, mesmo que o professor esteja preparado para expor os conteúdos teóricos, é de extrema relevância dar mais atenção e dedicação às aulas experimentais, tanto em sala de aula como no laboratório, podendo ambas serem bastante atrativas e proveitosas para os discentes.

Em relação às aulas experimentais, os PCN+ (BRASIL, 2002) apontam:

\footnotetext{
Há diferentes modalidades de realizá-las como experimento de laboratório, demonstrações em sala de aula e estudos do meio. Sua escolha depende de objetivos específicos do problema em estudo, das competências que se quer desenvolver e dos recursos materiais disponíveis (BRASIL, 2002, p. 108).
}

Mesmo sem laboratório, o professor pode lançar mão de recursos que são acessíveis aos alunos para preparar experiências de Química com materiais alternativos e simples, utilizando utensílios domésticos. Muitos desses experimentos podem ser realizados na própria sala de aula de modo a envolver a participação efetiva dos alunos. Se forem bem conduzidos, essas atividades se tornam importantes, pois, no mínimo, despertarão a atenção dos estudantes.

No entanto, para que isso aconteça são imprescindíveis a criatividade e a disponibilidade do professor, de maneira a proporcionar a execução de experimentos criativos e modestos, mas que deem bons resultados para melhoria do processo de ensino e de aprendizagem. 
5a questão: Que tipo de aulas você considera mais agradável?
a) ( ) Expositivas e teóricas
b) ( ) Práticas e experimentais opção b.

Resultado: 15,5\% (35 alunos) marcaram a opção a; e 84,5\% (191 alunos), a

As respostas de mais de $80,0 \%$ dos alunos demonstram que as aulas práticas e experimentais são as que eles consideram mais agradáveis.

Quanto a isso, Montenegro (2009) estima que, com a realização de atividades experimentais, é possível conhecer dos alunos o seu lado cooperador, participativo e comunicativo, de tal forma que o compartilhar entre si o que foi aprendido no decorrer do experimento torna a aula agradável e prazerosa.

Segundo Krasilchik (2004, p. 85), a função das aulas experimentais é "despertar e manter o interesse dos alunos; envolver os estudantes em investigações científicas; desenvolver a capacidade de resolver problemas; compreender conceitos básicos; desenvolver habilidades".

De acordo com Calil (2009), no entanto, há que considerar o fato de muitas escolas disporem de uma estrutura laboratorial adequada, mas não apresentarem equipamentos e/ou reagentes apropriados para a realização dos experimentos. Por outro lado, ou o docente não tem tempo disponível para planejar as aulas experimentais a serem desenvolvidas com seus alunos, ou o número excessivo de alunos por turma inviabiliza esse tipo de atividade. Tudo isso torna desmotivadora a realização de aulas mais prazerosas.

Neste sentido, vale também ressaltar o que Suart e Marcondes (2009) afirmam sobre isso:

\footnotetext{
As atividades experimentais, tanto no ensino médio como em muitas universidades, ainda são muitas vezes tratadas de forma acrítica e aproblemática. Pouca oportunidade é dada aos alunos no processo de coleta de dados, análise e elaboração de hipóteses. O professor é o detentor do conhecimento e a ciência é tratada de forma empírica e algorítmica. $\mathrm{O}$ aluno é o agente passivo da aula e a ele cabe seguir um protocolo proposto pelo professor para a atividade experimental, elaborar um relatório e tentar ao máximo se aproximar dos resultados já esperados (SUART; MARCONDES, 2009, p. 51).
}

Normalmente, quando bem planejadas e estruturadas, as aulas experimentais tendem a despertar maior interesse dos alunos do que as aulas expositivas, desde que apresentem caráter motivador, prazenteiro, divertido, lúdico e articulado aos sentidos, de maneira que possibilitem um maior envolvimento dos alunos, despertando-lhes curiosidades que os estimulem ao estudo e à compreensão dos conhecimentos químicos.

6a questão: Que tipo de aula você acha que aprende mais?
a) ( ) Expositivas e teóricas
b) ( ) Práticas e experimentais

Resultado: $25,7 \%$ (58 alunos) assinalaram a opção a; e 74,3\% (168 alunos), a opção b. 
Observamos que a grande maioria dos alunos, além de considerar mais agradáveis as aulas experimentais, que será discutido na questão 7, também assinalou ser esse tipo de aula aquele que proporciona um maior aprendizado.

Não queremos aqui desqualificar a metodologia cuja didática se fundamenta exclusivamente na aula expositiva. No entanto, pela quantidade de alunos que respondeu afirmando serem as aulas experimentais aquelas nas quais eles mais aprendem, seria o caso de os docentes repensarem a sua prática, buscando desenvolver aulas que possam mostrar uma Química mais experimental e prática, com os conhecimentos mais aplicáveis e acessíveis ao entendimento dos alunos.

Devemos reconhecer que não há como tornar a Química tão fascinante se não utilizarmos a experimentação como estratégia didática, pois, se bem desenvolvida, poderá tornar o Ensino de Química muito mais interessante para os jovens. Neste sentido, vale ressaltar o que afirmam as OCEM (BRASIL, 2006) sobre isso:

[...] é essencial que as atividades práticas, em vez de se restringirem aos procedimentos experimentais, permitam ricos momentos de estudo e discussão teórico/prática que, transcendendo os conhecimentos de nível fenomenológico e os saberes expressos pelos alunos, ajudem na compreensão teórico-conceitual da situação real, mediante o uso de linguagens e modelos explicativos específicos que, incapazes de serem produzidas de forma direta, dependem de interações fecundas na problematização e na (re)significação conceitual pela mediação do professor (BRASIL, 2006, p. 123-124).

As aulas experimentais fazem com que os estudantes observem, com os próprios olhos, o real sentido em aprender Química, a maneira como são descobertas e construídas as teorias a partir da experimentação. Não há como negar que as aulas práticas facilitam a aprendizagem, pois torna o conteúdo da disciplina envolvente, além de incentivar e despertar a curiosidade dos discentes, de maneira a estimular e desenvolver a capacidade de aprender.

Dessa forma, não há como deixar de acreditar que ensinar Química por meio de experimentos traz resultados bastante significativos para o aprendizado dos estudantes.

7ạ questão: Você já participou (manipulando os materiais) de alguma prática de Química?
a) ( ) $\operatorname{sim}$
b) ( ) não

Resultado: 51,4\% (116 alunos) marcaram a opção a; e 48,6\% (110 alunos), a opção b.

Para essa questão, os percentuais das respostas dos alunos ficaram praticamente em torno de 50,0\% para cada uma das duas opções.

Vale ressaltar que, apesar de $48,6 \%$ destes alunos terem assinalado a opção b (não), eles entendem do que se trata uma aula experimental, pois praticamente todos os livros didáticos de Química apresentam descrições e ilustrações mostrando vários experimentos, além de terem tido, em algum momento durante o Ensino Fundamental, a oportunidade de participar de uma aula prática. das transformações das substâncias químicas durante a realização dos 
experimentos que se poderiam explicar e construir os conceitos teóricos. Essa exortação do autor, proferida em seu trabalho publicado há 40 anos, continua sendo muito apropriada para o Ensino de Química desenvolvido pelas escolas nos dias atuais.

Segundo Ferreira, Hartwig e Oliveira (2010), para que as atividades experimentais adquiram significado pelos alunos

[...], é necessário conduzir as aulas de laboratório de maneira oposta às tradicionais. Isso significa que o professor deve considerar a importância de colocar os alunos frente a situações-problema adequadas, propiciando a construção do próprio conhecimento. No entanto, para que tais situaçõesproblema possam ser criadas, é fundamental que se considere a necessidade de envolvimento dos alunos com um problema (preferencialmente real) e contextualizado (FERREIRA; HARTWIG; OLIVEIRA, 2010, p. 101).

Portanto, para que seja possível se obter resultados mais satisfatórios no aprendizado dos conteúdos explorados nas aulas experimentais, é necessário que os alunos sejam sujeitos ativos durante o desenvolvimento das mesmas, de modo que possam participar efetivamente, desde a discussão da situação-problema colocada até o 'fazer a prática' (SCAFI, 2010).

Quando o objetivo maior da aula é mostrar o lado divertido e fantástico desta Ciência, a manipulação dos equipamentos, vidrarias e soluções possibilita um envolvimento muito maior dos alunos durante os experimentos. No contexto do Ensino de Química que ainda temos hoje em nossas escolas, a metodologia da aula prática é um diferencial que pode proporcionar uma participação entusiasmada, na qual os alunos se tornam, por meio da familiarização com os utensílios usados pela Química, sujeitos construtores de suas hipótese e teorias, ou seja, que constroem seus próprios saberes.

\section{8a questão: Você gostou de ter manipulado os materiais químicos?}

\section{a) ( ) $\operatorname{sim}$ b) ( ) não c) ( ) tive medo d) ( ) não manipulei}

Resultado: 39,9\% (90 alunos) marcaram a opção a; 2,6\% (06 alunos), a opção b; 8,9\% (20 alunos), a opção c; e 48,6\% (110 alunos), a opção d.

De acordo com as respostas, percebemos que um número de 90 alunos assinalou ter gostado da oportunidade de manipular os materiais e instrumentos químicos durante a realização dos experimentos.

Quem não gosta de manipular os materiais de um laboratório, ainda mais quando a finalidade maior é a realização de uma reação química cujas alterações que ocorrem com os reagentes provocam 'espanto' e 'curiosidade'? Por outro lado, o caráter didático-investigativo que o experimento pode proporcionar levará o estudante a se perguntar sobre o 'porquê' daquela reação química ocorrer, estimulando-o à descoberta e à compreensão dos conteúdos químicos. Estes e outros questionamentos possibilitarão ao estudante a construção dos muitos conceitos vinculados ao experimento, os quais seriam memorizados pelos alunos se a aula fosse expositiva.

Para Cardoso e Colinvaux (2000), quando se trata de um experimento realizado por meio da manipulação instrumental pelo próprio aluno, em que ele poderá dizer 'eu mesmo fiz', a busca das respostas aos questionamentos colocados 
pela situação-problema será mais estimulante para ele, fazendo-o aprender Química de maneira mais agradável. Além disso, com a participação do professor, o discente poderá discutir suas dúvidas e observações, fazendo gerar uma relação de maior confiança entre docente e discente.

No entanto, Gonçalves e Marques (2006, p. 232) chamam a atenção para o fato de que "as atividades experimentais não precisam ser compreendidas como atividades facilitadoras da aprendizagem conceitual, mas sim como um dos elementos desse processo".

9ạ questão: As aulas práticas de que você participou foram:

\section{a) ( ) Em grupo \\ b) ( ) Em dupla \\ c) ( ) Apenas o professor fez o experimento}

Resultado: 56,2\% (127 alunos) assinalaram a opção a; 6,6\% (15 alunos), a opção b; e 37,2\% (84 alunos), a opção c.

Mais da metade dos alunos assinalaram a opção contendo a expressão 'em grupo'. No entanto, um número expressivo deles $(37,2 \%)$, assinalou ter observado uma demonstração feita pelo professor, letra c.

Para Salvadego e Laburú (2009), independentemente de ser demonstrativa (quando o professor realiza o experimento) ou em grupo (quando os próprios alunos desenvolvem o experimento manipulando os materiais químicos), é importante que a aula conduzida por meio da experimentação proporcione os momentos para organização, discussão e análise da atividade prática, de modo a possibilitar a interpretação dos fenômenos químicos e a troca de saberes que ocorrem entre os membros do grupo durante o experimento.

Neste sentido, de acordo com Gaspar (2003), existem algumas vantagens das aulas experimentais em relação as aulas expositivas:

\footnotetext{
$\mathrm{Na}$ atividade experimental os parceiros discutem as mesmas ideias e respondem às mesmas perguntas favorecendo o desenvolvimento da interação social. Enquanto que, na atividade teórica deve-se recorrer a enunciados verbais cuja compreensão nunca é simples e óbvia. [...] A segunda vantagem da atividade experimental sobre a teórica está na riqueza da interação social que ela desencadeia. A atividade teórica é limitada pelo enunciado, o qual restringe as condições iniciais para que haja procedimentos e respostas convergentes (GASPAR, 2003, p. 24).
}

Na concepção construtivista, o professor tem a função de promover atividades que possibilitem ao aluno questionar, refletir e atuar. Neste sentido, independentemente da modalidade da aula (em dupla, em grupo ou realizada pelo professor), quando as atividades experimentais são realizadas em ambientes diferentes da sala de aula, que favorecem os trabalhos em conjunto, tornam-se ocasiões excelentes para o professor desempenhar plenamente sua função, possibilitando ao aluno pensar, refletir e dar significado ao que aprende. Desse modo, a aula experimental no Ensino Médio pode se constituir em uma atividade ideal para discussão e problematização dos conteúdos químicos, pedagogicamente orientada pelo professor. 
10 a questão: Atribua uma nota de 1 a 10 às aulas experimentais de Química que você já teve:

Resultado:

NOTA Número de alunos Percentagem (\%)

$\begin{array}{lll}1,0 \text { a } 5,0 & 24 & 10,6 \\ 6,0 \text { a } 7,5 & 50 & 22,2 \\ 8,0 \text { a } 10,0 & 152 & 67,2\end{array}$

Para esta questão, 202 alunos (89,4\%) atribuíram notas iguais ou superiores a 6,0 às aulas experimentais de Química das quais participaram.

Esses resultados ratificam as proposições que afirmam ser esse tipo de aula mais estimulante para um melhor aprendizado dos alunos, além de ser mais prazerosa (SANTOS; FRIGERI, 2013; DELIZOICOV; ANGOTTI; PERNAMBUCO, 2011).

Neste sentido, Guimarães (2009) também afirma que uma das maneiras mais eficazes de se ensinar ciências é por meio das aulas experimentais, pois não será necessário ao educando conhecer muito da teoria para compreender o desenvolvimento de um determinado experimento. No entanto, Benite e Benite (2009) enfatizam que esta metodologia só será válida se suscitar no aluno a vontade de buscar compreender as teorias científicas que levaram àquele experimento e os conhecimentos científicos que serão construídos a partir dele.

Devemos ainda considerar nessa avaliação dos alunos, o fato de eles terem participado de poucas aulas experimentais (ou nenhuma), de maneira que, provavelmente, não foi o suficiente para despertar, em muitos deles, a sensação de estar aprendendo Química como os cientistas aprendem e descobrem coisas novas, o que é bastante estimulante e prazeroso. Além disso, também há que considerar como essas aulas experimentais estão sendo desenvolvidas, pois, se não forem bem planejadas e conduzidas, podem se tornar menos atrativas que as aulas teóricas.

11a questão: Atribua uma nota de 1 a 10 às aulas expositivas de química:

Resultado:

NOTA Número de alunos Percentagem (\%)

$\begin{array}{lll}1,0 \text { a } 5,0 & 28 & 12,4 \\ 6,0 \text { a } 7,5 & 58 & 25,6 \\ 8,0 \text { a } 10,0 & 140 & 62,0\end{array}$

O número de alunos que atribuiu notas acima de 6,0 às aulas expositivas foi bastante significativo (87,6\%). Em se tratando da disciplina de Química, este resultado é bastante positivo. No entanto, a quantidade de alunos que atribuiu notas entre 8,0 e 10,0 às aulas expositivas apresentou 5,2\% a menos, quando comparada com a quantidade de alunos que atribuíram notas nesta mesma faixa às aulas experimentais (Questão 12). Isso indica que há uma certa preferência dos alunos por estas últimas. 
Estas observações nos fazem compreender que há uma relação muito estreita entre teoria e prática no Ensino de Química, de modo que uma dessas estratégias didáticas não pode prevalecer em detrimento da outra. Enquanto professores de Química, devemos saber da importância de relacionarmos aulas expositivas e experimentais, pois ambas abordagens didáticas, quando bem trabalhadas, possibilitam aos alunos oportunidades de atingirem um melhor desenvolvimento cognitivo.

Para Krasilchik (2004), há várias décadas, as aulas expositivas vêm sendo as mais utilizadas como única modalidade didática no Ensino das ciências, incluída a Química. Elas têm por finalidade "introduzir um assunto novo, sintetizar um tópico ou comunicar experiências pessoais do professor" (p. 79). Nesse método de ensino não há a participação ativa dos discentes e nem uma interação maior com o professor. Ainda segundo a autora, as aulas expositivas não são a metodologia ideal para um Ensino de Ciências mais satisfatório, pois

\footnotetext{
A introdução das aulas não é feita de modo a captar a atenção da classe e motivar os estudantes, pelo que cria uma situação inesperada, conflitante ou muito complexa. [...] A exemplificação usada nas aulas ou é excessiva, fazendo os alunos perderem o fio da exposição, ou é deficiente e inadequada, dificultando a compreensão. [...] As aulas são mal preparadas, de forma que os alunos não percebem seu plano geral e não podem acompanhar a exposição do professor. [...] Os professores, ambiciosamente, pretendem dar mais conteúdo do que é possível no tempo disponível, prejudicando o resultado total (KRASILCHIK, 2004, p. 79).
}

Embora estas desvantagens das aulas expositivas sejam amplamente conhecidas, as aulas de Química continuam a se processar sob essa forma: os professores reproduzem e repassam os seus conhecimentos, cabendo aos alunos apenas memorizá-los e reproduzi-los da mesma forma como lhes foram repassados (BRASIL, 1999).

As aulas expositivas são alvo de muitas críticas, no entanto não podemos atribuir somente características negativas a essa metodologia. O que devemos levar em consideração é a necessidade de mudar a forma como a aula expositiva é aplicada em sala de aula, pois, se o docente tiver as competências e as habilidades necessárias, ele poderá transformá-la em uma exposição dinâmica, participativa e estimuladora do pensamento crítico dos alunos.

12a questão: Se você fosse professor de Química, o que você faria para melhorar suas aulas?

Entre as sugestões mais expressivas estão: 68,6\% (155 alunos) propuseram mais aulas práticas e experimentais; 7,9\% (18 alunos) disseram 'não mudar nada'; 7,0\% (16 alunos) sugeriram aulas com dinâmicas; 4,0\% (09 alunos) disseram que faria um equilíbrio entre aulas teóricas e práticas; 3,5\% (08 alunos) inovariam no Ensino de Química. Os outros 9,0\% (20 alunos) diversificaram bastante suas sugestões, sem atingir uma expressividade numérica.

Os alunos enumeraram cerca de 12 (doze) sugestões, mas consideramos somente 05 (cinco) delas com percentagens suficientes para suscitar uma discussão. Assim, dentre aquelas que mais chamaram nossa atenção, destacamos a grande preocupação dos alunos em incrementar o número de aulas práticas e experimentais, já que $68,6 \%$ a citaram. 
Possivelmente esta grande percentagem para o item se deva ao fato dos estudantes considerarem as aulas experimentais mais interessantes e motivadoras, além de possibilitar uma associação mais significativa entre a teoria e a prática na Química (SUART; MARCONDES, 2009).

Neste sentido, os alunos também citaram a utilização de outros recursos didático-pedagógicos, como o uso de dinâmicas, aulas de campo e aulas mais interativas com recursos didáticos tecnológicos. Alguns estudantes também mencionaram a necessidade de uma maior clareza e objetividade das aulas da disciplina, buscando focar uma melhor contextualização dos conteúdos trabalhados no Ensino de Química.

Um número de 05 (cinco) alunos do 1ㅇano, que foram incluídos entre aqueles que 'não mudariam nada', fizeram os seguintes comentários: "Ficava só na cadeira do professor sentado esperando a aula acabar"; "Primeira coisa eu nunca seria professor de Química, porque é a única matéria que eu não gosto nada"; "eu não acho nada porque eu nunca quero ser professora de química"; "Trazia bolas para sala de aula"; "Jogava bola na sala". Essas falas demonstram a aversão que, geralmente, a grande maioria dos alunos do Ensino Médio dispensam à disciplina de Química.

Gostaríamos de ressaltar as opiniões de 03 (três) alunos do $3^{\circ}$ ano: "Iria com os meus alunos com mais frequência ao laboratório para usufruir do material que a escola disponibiliza"; [sic] "Aulas teóricas cansa muito"; "Aulas diferentes pelo menos a cada 15 dias".

Como esperado, os alunos do $3^{\circ}$ ano parecem demonstrar uma certa maturidade, de modo a conceber uma visão didático-metodológica mais elaborada. Podemos perceber que eles têm uma preocupação em inovar e renovar o Ensino de Química, com aulas experimentais e diferentes. Talvez esses sentimentos estejam ligados ao desejo de 'sair da mesmice' em que se encontra o Ensino de Química no Terceiro Ano, durante o qual os conteúdos de Química Orgânica são explorados, na maioria das vezes, apenas de forma teórica, expositiva e/ou memoriável (ZANON; GUERREIRO; OLIVEIRA, 2008).

\section{CONSIDERAÇÕES FINAIS}

Os resultados desta pesquisa indicam que nestas Escolas ainda predomina um ensino tradicional, fundamentado quase que exclusivamente em aulas teóricoexpositivas. Raramente os estudantes são chamados a desenvolverem, junto com o professor, experimentos envolvendo os conteúdos de Química. Provavelmente os poucos experimentos dos quais esses alunos participaram serviram apenas para confirmar, em alguns momentos, os conceitos químicos que os professores expuseram nas aulas teóricas.

De acordo com a opinião dos alunos entrevistados, para tornar o Ensino de Química mais satisfatório seria necessário desenvolver aulas práticas e experimentais com mais frequência, pois as atividades dessa natureza tornam o estudo da Química mais interessante e motivador.

Neste sentido, ressaltamos a importância de que essas atividades devam ser norteadas de um planejamento capaz de torná-las verdadeiramente instrumentos de aprendizagem, ou seja, elas não podem mais se constituir em apenas 'seguir 
uma receita de bolo' ou em 'um show de efeitos visuais'. É preciso que o professor se conscientize da necessidade de uma abordagem contextualizada por meio da experimentação de uma situação-problema, na qual o aluno enfrentará o desafio de buscar as respostas para os vários questionamentos que serão construídos por ele.

Outra sugestão colocada pelos alunos aventa que sejam utilizados também outros recursos didático-pedagógicos, como por exemplo, dinâmicas, atividades de campo e ações que oportunizem maior interatividade com equipamentos tecnológicos mais modernos, preterindo o quadro e o pincel. Além disso, os discentes também salientaram a necessidade de apresentação de aulas com maior clareza e objetividade, de modo que, sejam elas expositivas ou experimentais, devem estar em sintonia com o processo de contextualização do Ensino.

No entanto, sabemos que mudanças no processo de ensino e de aprendizagem de Química só serão possíveis se houver envolvimento de todos que fazem parte do processo educacional, professores, alunos, gestores, comunidade e, principalmente aqueles que gerenciam as políticas públicas no setor da Educação.

Por outro lado, para que possamos conquistar um Ensino de Química satisfatório, é necessário que os docentes descubram a Química como Ciência essencialmente experimental, entendendo que todo o seu discurso teórico foi elaborado a partir da observação de fenômenos naturais ou de experimentos conduzidos pelos cientistas. Em outras palavras, é necessário que construamos uma didática para um Ensino de Química mais experimental, no qual os educadores químicos assumam e desempenhem o papel de articuladores epistemológicos, de modo a possibilitar o fluxo de conhecimentos entre os conteúdos tratados nas aulas expositivas e aqueles explorados nas aulas experimentais.

Se os professores, principais agentes articuladores do processo de ensino e de aprendizagem, assumirem uma nova postura didática na abordagem dos conteúdos químicos, de maneira a explorar mais intensamente o caráter experimental e prático da Química, talvez seja possível diminuir o sentimento de rejeição e antipatia que a maior parte dos alunos do Ensino Básico dedicam a esta disciplina. 


\title{
Experimental classes to a teaching of chemistry more satisfactory
}

\begin{abstract}
The objective of this work was to present the results of an investigation that aimed to identify the view of High School students on the role of theoretical and practical classes in chemistry learning. To collect data, we applied a questionnaire to 226 students in three years of high school. By analyzing the responses, we noticed that the chemistry teachers of these students develop a learning rarely based experimental classes. According to these students, a most satisfactory Chemistry Teaching require more classes of this kind, which make the study of this Science more interesting and motivating. Students also mentioned the need for a teaching more contextualized, with lessons having greater clarity and objectivity.
\end{abstract}

KEYWORDS: Chemistry teaching. Experimental class. Theoretical class. 


\section{REFERÊNCIAS}

ALVES, I. M. R. Aulas teóricas e aulas práticas: algumas reflexões a partir do olhar dos estudantes de química do ensino médio. 2014. 53 f. Monografia (Graduação em Licenciatura Plena em Química) - Faculdade de Educação de Crateús, Universidade Estadual do Ceará, Crateús, 2014.

ALVES, W. F. A formação de professores e as teorias do saber docente: contexto, dúvidas e desafios. Revista Educação e Pesquisa, v. 33. n. 2. p. 263-280, 2007.

BENITE, A. M. C.; BENITE, C. R. M. O laboratório didático no ensino de química: uma experiência no ensino público brasileiro. Revista Iberoamericana de Educación, v. 48, n. 2, p. 1-10, 2009.

BENITE, C. R. M.; BENITE, A. M. C.; ECHEVERRIA, A. R. A pesquisa na formação de formadores de professores: em foco, a Educação Química. Química Nova na Escola, v. 32, n. 4, p. 257-266, 2010.

BORGES, A. T. Novos Rumos para o laboratório escolar de ciências. Caderno Brasileiro de Ensino de Física, v. 19, n.3, p. 291-313, 2002.

BRASIL. Orientações Curriculares para o Ensino Médio: ciências da natureza, matemática e suas tecnologias. Vol 2. Brasília: MEC/SEB, 2006.

\section{Orientações Educacionais Complementares aos Parâmetros}

Curriculares Nacionais ( $\mathrm{PCN}+)$ : ciências da natureza, matemática e suas Tecnologias. Brasília: MEC/SEMTEC, 2002.

Parâmetros Curriculares Nacionais (Ensino Médio). Parte III - Ciências da natureza, matemática e suas tecnologias. Brasília: MEC/SEB, 1999.

BUONFIGLIO, A. Uma didática história da química: da filosofia grega à contribuição dos alquimistas da antiguidade, as ideias, os experimentos e teorias que configuraram a química como ciência. ComCiência, s/v, n. 130, p. 1-2, 2011. 
CARDOSO, S. P.; COLINVAUX, D. Explorando a motivação para estudar química. Química Nova, v. 23, n. 3, p. 401-404, 2000.

DELIZOICOV, D.; ANGOTTI, J. A.; PERNAMBUCO, M. M. Ensino de ciências: fundamentos e métodos. São Paulo: Cortez, 2011.

DOMINGUEZ, S. F. As Experiências em Química. São Paulo: EDART, 1975.

FERREIRA, L. H.; HARTWIG, D. R.; OLIVEIRA, R. C. Ensino Experimental de Química: uma abordagem investigativa contextualizada. Química Nova na Escola, v. 32, n. 2, p. 101-106, 2010.

GALIAZZI, M. C.; GONÇALVES, F. P. A natureza pedagógica da experimentação: uma pesquisa na Licenciatura Plena em Química. Química Nova, v. 27, n. 2, p. 326-331, 2004.

GASPAR, A. Experiências de ciências para o Ensino Fundamental. São Paulo: Ática, 2003.

GERHARD, A. C.; FILHO, J. B. R. A Fragmentação dos saberes na educação científica escolar na percepção de professores de uma escola de Ensino Médio. Investigações em Ensino de Ciências, v. 17, n. 1, p. 125-145, 2012.

GONÇALVES, F. P.; MARQUES, C. A. Contribuições pedagógicas e epistemológicas em textos de experimentação no Ensino de Química. Investigações em Ensino de Ciências, v. 11, n. 2, p. 219-238, 2006.

GUIMARÃES, C. C. Experimentação no ensino de Química: caminhos e descaminhos rumo à aprendizagem significativa. Química Nova na Escola, v. 31, n. 3, p. 198-202, 2009.

KRASILCHIK, M. Prática de Ensino de Biologia. São Paulo: EDUSP, 2004.

LEAL, M. C. Didática da Química: fundamentos e práticas para o ensino médio. Belo Horizonte: Dimensão, 2010.

LEITE, L. Contributos para uma utilização mais fundamentada do trabalho laboratorial no Ensino das Ciências. In CAETANO, H. V.; SANTOS, M. G. Cadernos Didácticos de Ciências, vol. 1. Lisboa: Ministério da Educação, 2001, p. 77-96. 
LÜDKE, M.; ANDRÉ, M. E. D. A. Pesquisa em educação: abordagens qualitativas. Rio de Janeiro: EPU, 2013.

MAIA, J. O.; SILVA, A. F. A.; WARTHA, E. J. Um retrato do ensino de química nas escolas de ensino médio de Itabuna e Ilhéus, BA. 14. Curitiba: 2008. 11 p. Disponível em: http://www.quimica.ufpr.br/eduquim/eneq2008/resumos/R0400-2.pdf. Acesso em: 13 set. 2013.

MALDANER, O. A. A Formação Inicial e Continuada de Professores de Química Professores /Pesquisadores. 3 ed. Ijuí: UNIJUÍ, 2006.

MALHEIROS, B. T. Metodologia da pesquisa em educação. Rio de Janeiro: LTC, 2011.

MATEUS, A. L. Química na Cabeça 2: mais experimentos espetaculares para você fazer em casa ou na escola. Belo Horizonte: UFMG, 2010.

MONTENEGRO, D. S. Experimentação no Ensino de Química. 2009. 38 f. Monografia (Graduação em Licenciatura Plena em Química) - Universidade Estadual da Paraíba, Campina Grande, 2009.

PINTO, A. C. O ensino médio de química: o que fazer para melhorá-lo? Journal of the Brazilian Chemical Society, v. 23, n. 6, p. 985-986, 2012.

RUSHTON, G. T.; LOTTER, C.; SINGER, J. Chemistry teachers' emerging expertise in inquiry teaching: the effect of a professional development model on beliefs and practice. Journal of Science Teacher Education, v. 22, n. 1, p. 23-52, 2011.

SALVADEGO, W. N. C.; LABURÚ, C. E. Uma análise das relações do saber profissional do professor do ensino médio com a atividade experimental no Ensino de Química. Química Nova na Escola, v. 31, n. 3, p. 216-223, 2009.

SANTOS, V. M. C.; FRIGERI, H. R. A necessidade da experimentação no ensino de Química. XI Congresso Nacional de Educação. Curitiba: 2013. Disponível em: http://educere.bruc.com.br/ANAIS2013/pdf/10246_6608.pdf. Acesso em: 19 fev. 2014.

SCAFI, S. H. F. Contextualização do ensino de química em uma escola militar. Química Nova na Escola, v. 32, n. 3, p. 176-183, 2010. 
SILVA, A. M. Proposta para tornar o ensino de Química mais atraente. 2011. Disponível em: <http://www.abq.org.br/rqi/2011/ 731/RQI-731-pagina7Proposta-para Tornar-o-Ensino-de-Quimica-mais-Atraente.pdf>. Acesso: 20 ago. 2013.

SILVA, R. R.; MACHADO, P. F. L. Experimentação no ensino médio de química: a necessária busca da consciência ético-ambiental no uso e descarte de produtos químicos: um estudo de caso. Ciência \& Educação, v. 14, n. 2, p. 233-249, 2008.

SUART, R. C.; MARCONDES, M. E. R. A manifestação de habilidades cognitivas em atividades experimentais investigativas no ensino médio de química. Ciências \& Cognição, v. 14, n. 1, p. 50-74, 2009.

TREVISAN, T. S.; MARTINS, P. L. O. O professor de Química e as aulas práticas. 2008. Disponível em:

<http://www.pucpr.br/eventos/educere/educere2008/anais/pdf/365_645.pdf>. Acesso: 31 mai. 2012.

ZANON, D. A. V.; GUERREIRO, M. A. da S.; OLIVEIRA, R. C. de. Jogo didático Ludo Químico para o ensino de nomenclatura dos compostos orgânicos: projeto, produção, aplicação e avaliação. Ciências \& Cognição, v. 13, n. 1, p. 72-81, 2008.

Recebido: 28 abri. 2015

Aprovado: 05 mar. 2016.

DOI: $10.3895 /$ rbect.v9n1.2913

Como citar:

LIMA, J. O. G.; ALVES, I. M. R. Aulas experimentais para um ensino de Química mais significativo. Revista

Brasileira de Ensino de Ciência e Tecnologia, v. 9, n. 1, p. 428-447, jan./abr. 2016. Disponível em:

<https://periodicos.utfpr.edu.br/rbect/article/view/2913>. Acesso em: xxx.

Correspondência:

José Ossian Gadelha de Lima

Rua Juarez Távora, 132, 63700-000, Crateús, Ceará

Idarlene Marcelino Rodrigues Alves

Rua Antônio Rufino Vieira, 100, 63740-000, Novo Oriente, Ceará

Direito autoral: Este artigo está licenciado sob os termos da Licença Creative Commons-Atribuição 4.0 Internacional.

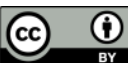

